BRIEF COMMUNICATION

\title{
Lack of germline transmission in male mice following a single intravenous administration of AAV5-hFVIII-SQ gene therapy
}

Carlos Fonck ${ }^{1,6}$, Cheng $\mathrm{Su}^{2,6}$, Jeremy Arens ${ }^{1,6}$, Elli Koziol ${ }^{1}$, Jaydeep Srimani ${ }^{3}$, Joshua Henshaw ${ }^{3}$, Andrea Van Tuyl ${ }^{4}$, Sundeep Chandra $^{5}$, Christian Vettermann (iD ${ }^{4}$ and Charles A. O'Neill ${ }^{1 \times}$

(c) The Author(s) 2022

Valoctocogene roxaparvovec (AAV5-hFVIII-SQ) is an adeno-associated virus serotype five gene therapy under investigation for the treatment of hemophilia A. Herein, we assessed the potential for germline transmission of AAV5-hFVIII-SQ in mice. Male B6.129S6Rag2 ${ }^{\text {tm1Fwa }}$ N12 mice received a single intravenous dose of vehicle or $6 \times 10^{13} \mathrm{vg} / \mathrm{kg}$ AAV5-hFVIII-SQ. Vehicle and AAV5-hFVIII-SQtreated mice were mated with naïve females 4 days after dosing, when the concentration of vector genomes was expected to be at its peak in semen, and 37 days after dosing, when a full spermatogenesis cycle was estimated to be complete. Quantitative PCR was used to evaluate the presence of transgene DNA in liver and testes from F0 males dosed with AAV5-hFVIII-SQ and liver tissue of F1 offspring. Transgene DNA was detected in liver and testes of all F0 males dosed with AAV5-hFVIII-SQ, confirming successful transduction. Importantly, no transgene DNA was detected in any tested F1 offspring derived from F0 males dosed with AAV5hFVIII-SQ. Using a novel 2-stage statistical model that takes into account the number of males dosed with AAV5-hFVIII-SQ and the number of offspring sired by these males, we estimate that the risk of germline transmission is $<5 \%$ with a $99.2 \%$ confidence level.

Gene Therapy; https://doi.org/10.1038/s41434-022-00318-5

\section{INTRODUCTION}

Hemophilia A is an X-linked bleeding disorder caused by mutations in the Factor VIII (FVIII) gene that affects approximately 1 in 5000 males worldwide [1]. People with severe hemophilia A (FVIII $\leq 1 \mathrm{IU} /$ $\mathrm{dL}$ ) are at risk of spontaneous bleeding, joint damage that can result in disabling arthropathy, and in some cases, fatal brain hemorrhages $[2,3]$. Valoctocogene roxaparvovec (AAV5-hFVIII-SQ) is an adenoassociated virus serotype 5 (AAV5) vector that contains a coding sequence for the human Factor VIII-SQ (hFVIII-SQ) protein. We previously showed that AAV5-hFVIII-SQ gene therapy results in safe and efficacious expression of hFVIII-SQ protein in mice lacking FVIII and clinical trial participants with severe hemophilia A [4-7].

Systemically-delivered AAV-based gene therapies often result in a wide distribution of vector genomes to multiple tissues, including gonads [8-12]. In clinical trials, residual AAV5-hFVIII-SQ vector DNA was detected in seminal fluid for up to 12 months following a single administration, albeit no vector DNA was detected in sperm cells [6]. Therefore, an important concern regarding AAV-mediated gene transfer for the treatment of somatic diseases is the potential for transgene DNA to be incorporated into the human germline.

Various approaches have been pursued to investigate the potential for AAV-based gene therapies to cause germline transmission, including the detection and quantitation of transgene DNA in the gonads and/or in the offspring of animals that received AAV-based gene therapy [8-17]. In this study, the potential for germline transmission of AAV5-hFVIII-SQ was evaluated in male B6.129S6-Rag2 ${ }^{\text {tmiFwa }} \mathrm{N} 12$ mice, which lack the
RAG2 gene necessary for mature $\mathrm{T}$ and $\mathrm{B}$ lymphocyte production and are thus unable to mount a humoral immune response against the hFVIII-SQ transgene protein [18]. Male mice dosed with AAV5-hFVIII-SQ were bred with naïve females, and offspring were evaluated for the presence of transgene DNA.

This study features a 2-stage statistical model that assumes two distinct events need to occur for successful germline transmission: first, F0 males that received AAV5-hFVIII-SQ acquired and transmitted the transgene DNA to their offspring ( $F 1$ generation), and second, F1 mice inherited and retained the AAV5-hFVIII-SQ transgene DNA. This statistical model was first used to perform a power analysis calculation, based on hypothetical probabilities assigned to the two events above, that determined the minimal number of F0 and F1 mice necessary to detect at least one successful germline transmission event. The model was then used to establish a confidence level based on the results to qualify the claim that AAV5-hFVIII-SQ is not transmitted to the next generation via the germline.

\section{MATERIALS AND METHODS}

\section{Study design}

AAV5-hFVIII-SQ is a recombinant, replication-incompetent AAV5 vector that contains a single-stranded, codon-optimized hFVIII-SQ coding sequence controlled by a liver-selective promoter $[4,6]$. The concentration of AAV5-hFVIII-SQ dosing solution was determined via a titration method based on quantitative PCR (qPCR). A dose of $6 \times 10^{13} \mathrm{vg} / \mathrm{kg}$ AAV5-hFVIII-SQ was selected for this study because it was the highest dose utilized in

\footnotetext{
${ }^{1}$ Pharmacological Sciences, BioMarin Pharmaceutical Inc., Novato, CA, USA. ${ }^{2}$ Data Sciences and Analytics, BioMarin Pharmaceutical Inc., Novato, CA, USA. ${ }^{3}$ Clinical Pharmacology, BioMarin Pharmaceutical Inc., Novato, CA, USA. ${ }^{4}$ BioAnalytical Sciences, BioMarin Pharmaceutical Inc., Novato, CA, USA. ${ }^{5}$ Pathology, BioMarin Pharmaceutical Inc., Novato, CA, USA. ${ }^{6}$ These authors contributed equally: Carlos Fonck, Cheng Su, Jeremy Arens. ${ }^{凶}$ email: coneill@bmrn.com
}

Received: 29 June 2021 Revised: 20 December 2021 Accepted: 13 January 2022

Published online: 07 February 2022 


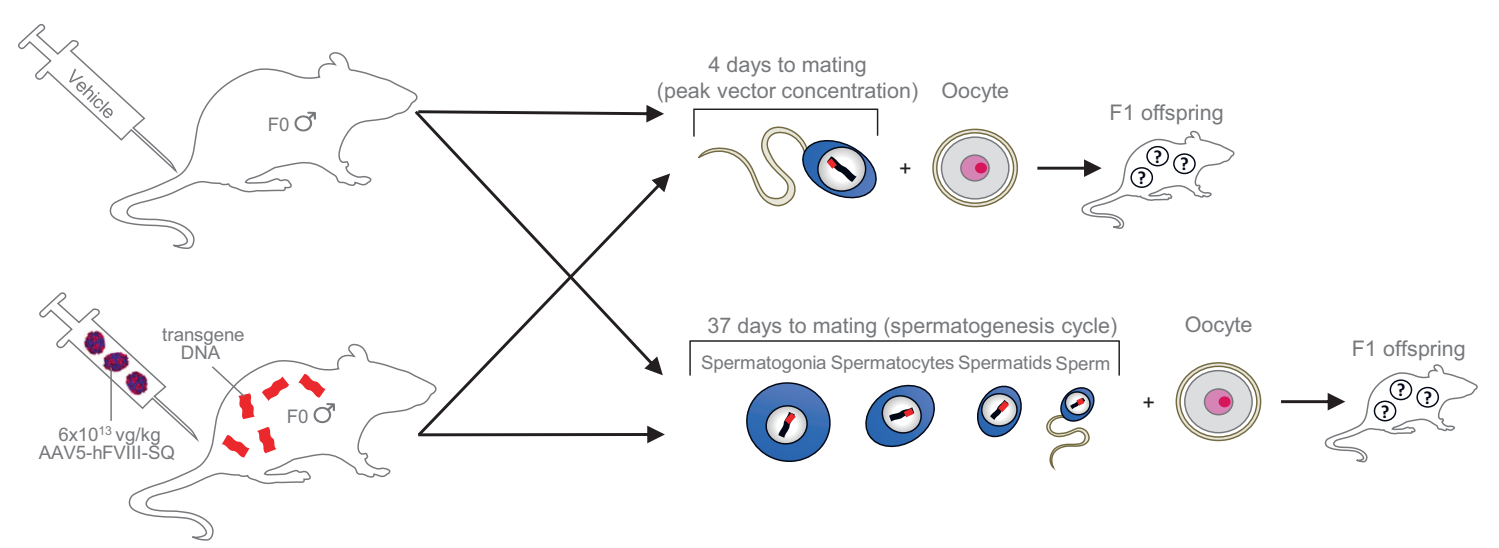

Fig. 1 Study design schematic. FO male mice received an injection of either vehicle or $6 \times 10^{13} \mathrm{vg} / \mathrm{kg}$ AAV5-hFVIII-SQ and were mated afterward at two different timepoints to naïve females. Some FO males were mated 4 days afterward, when transgene DNA in semen was estimated to be at peak concentration, and some were mated 37 days after injection, when a full spermatogenesis cycle was expected to complete. F0 males were assessed for transgene DNA in the testes and liver and for hFVIII-SQ protein in plasma. F1 pups were assessed for transgene DNA in the liver. hFVIII human Factor VIII.

clinical trials [5-7]. The vehicle control consisted of $10 \mathrm{mM}$ sodium phosphate, $140 \mathrm{mM}$ sodium chloride, $2 \%$ mannitol, and $0.2 \%$ pluronic F-68. Male B6.129S6-Rag2 ${ }^{\text {tmifwa }}$ N12 mice, which lack mature B and T lymphocytes, were administered a single intravenous injection of vehicle or $6 \times 10^{13} \mathrm{vg} / \mathrm{kg}$ AAV5-hFVIII-SQ into the tail vein (Fig. 1). Eight mice who received vehicle and 16 mice who received AAV5-hFVIII-SQ were mated with naïve B6.129S6-Rag2 ${ }^{\text {tm1Fwa }} \mathrm{N} 12$ females 4 days after dosing, when the concentration of vector genomes was estimated to be at its peak in semen, based on the shedding profile of 7 participants who received AAV5-hFVIIISQ (median time-to-peak, 1.29 weeks) [6]. Six mice who received vehicle and 34 mice who received AAV5-hFVIII-SQ were mated 37 days after dosing, when a full spermatogenesis cycle was expected to be complete [19-21]. Mice were randomly assigned to treatment groups. Animals were cohabitated for up to 9 days until mating occurred. F0 male mice mated early were euthanized 14 days post-dose, and F0 mice mated later were euthanized 50 days post-dose. Liver, testes, and blood samples were taken for molecular analyses. F1 pups had liver tissue harvested on postpartum day 21; pups found dead between days 1 and 20 were also collected for analysis.

Analysis of livers for transgene DNA was considered sufficient to assess the risk of germline transmission, as transgene DNA would be present in every cell of the F1 generation if a permanent modification had occurred in the F0 male germline. This is because transgene DNA integration into the host genome is required for stable germline transmission, given that nonintegrated transgene DNA (ie, episomal DNA) would be diluted and eliminated through the millions of cell divisions that occur during F1 embryogenesis and not be inherited through the germline. Therefore, if no transgene DNA was found in the livers of F1 mice, it can be assumed that transgene DNA did not cause inheritable FO germline modifications that would lead to multigenerational germline transmission.

This study was performed in compliance with the principles of Good Laboratory Practice. All animal housing and study procedures complied with the Guide of the Care and Use of Laboratory Animals [22], and the protocol was approved by the Institutional Animal Care and Use Committee before initiation. Throughout the study period, viability checks and clinical observations, including body weight and general appearance, were made regularly. F0 and F1 mice were euthanized by carbon dioxide asphyxiation, after which tissue and blood samples were collected and preserved for molecular analyses.

\section{qPCR method}

The tissue for $\mathrm{qPCR}$ analysis was flash frozen in liquid nitrogen and stored at $-70^{\circ} \mathrm{C}$. DNA was extracted using the QIAsymphony DSP DNA Mini kit and Qiagen Reagent DX (Qiagen, Hilden, Germany). DNA samples were diluted to a uniform concentration of $0.2 \mu \mathrm{g} / \mu \mathrm{L}$ and stored at $-20^{\circ} \mathrm{C}$. $\mathrm{gPCR}$ was performed to detect and measure transgene DNA present in tissue samples. A serial dilution of linearized FVIII-SQ plasmid was used as a positive control to generate a standard curve. A bulk master mix consisting of 1x TaqMan Environmental Master Mix (Sigma-Aldrich, St. Louis, MO), $900 \mathrm{nM}$ FVIII-SQ forward and reverse primer, and $250 \mathrm{nM}$ FVIII-SQ probe was used for qPCR (Supplementary Table 1). Primers and probe were validated to be specific for codon-optimized hFVIII-SQ and did not crossreact with genomic DNA murine FVIII sequences. Extracted study samples containing up to $1 \mu \mathrm{g}$ DNA were run in triplicate along with negative and positive controls in a QuantStudio Flex Real-Time PCR instrument (Thermo Fisher Scientific, Waltham, MA) with standard cycling conditions. Fluorescence was read and DNA quantification was performed by the QuantStudio Flex Real-Time PCR system. Samples were considered negative only if no increase of fluorescence above the threshold was observed after 40 amplification cycles. The validated limit of detection with $95 \%$ detectability was 7.28 copies/reaction.

\section{Electrochemiluminesence assay}

An antibody-based sandwich electrochemiluminescence (ECL) assay was performed to detect and quantitate hFVIII-SQ protein in plasma samples from F0 males. Whole blood samples were stored with a $3.2 \%$ sodium citrate anticoagulant solution and centrifuged within 30 min of collection to separate plasma, which was then stored at $-70^{\circ} \mathrm{C}$. An affinity-purified mouse monoclonal antibody to the $\mathrm{A} 2$ domain of $\mathrm{hFVIII}$ conjugated to an extra-long chain, amine reactive $\mathrm{N}$-hydrosulfosuccinimide biotin and an affinity-purified sheep polyclonal antibody conjugated to a ruthenium $\mathrm{N}$-hydroxysulfosuccinimide tag were incubated together with plasma samples at room temperature with shaking to form complexes between $\mathrm{hFVIII} \mathrm{and} \mathrm{the} \mathrm{tagged} \mathrm{antibodies.} \mathrm{The} \mathrm{mixture} \mathrm{was} \mathrm{then} \mathrm{pipetted} \mathrm{onto} \mathrm{a}$ plate blocked with $6 \%$ bovine serum albumin in Tris Buffered Saline with Tween 20 and incubated at room temperature with shaking to capture the biotin tags. Plates were triple washed and buffer-containing tripropylamine substrate was added to react electrochemically with the ruthenium. Antibody complexes containing hFVIII-SQ bound to both the biotinylated and ruthenylated antibodies generated ECL signals proportional to the amount of hFVIII-SQ present in the sample, which were detected and quantified by a Sector Imager 2400 plate reader (Meso Scale Discovery, Rockville, MA).

\section{Statistical methods}

A novel 2-stage model was used to assess germline transmission from F0 males to F1 offspring, assuming two distinct events need to occur for a successful germline transmission: 1) F0 males that received AAV5-hFVIII-SQ acquire transgene DNA and transmit it to the F1 generation, and 2) F1 generation mice inherit and retain the transgene DNA. Under this statistical model, the probability of detecting germline transmission in at least 1 of the $\mathrm{F} 1$ offspring is given in the following equation.

Probability of detecting transgene DNA in $\geq 1 \mathrm{~F} 1$ offspring $=1-\prod_{i=1}^{N}\left[1-P_{1}+P_{1} *\left(1-P_{2}\right)^{m_{i}}\right]$

$P_{1}$ is the probability that an F0 male acquires and transmits transgene DNA to its $F 1$ offspring; $P_{2}$ is the probability that the F1 offspring inherits and retains the transgene DNA; $P_{1}{ }^{*} P_{2}$ is the total probability of germline transmission; $N$ is the number of F0 males that had successful mating resulting in F1 offspring; and $m_{i}$ is the number of F1 offspring from the $i^{t h}$ F0 male. Study power was calculated to estimate the number of F0 males 
A)

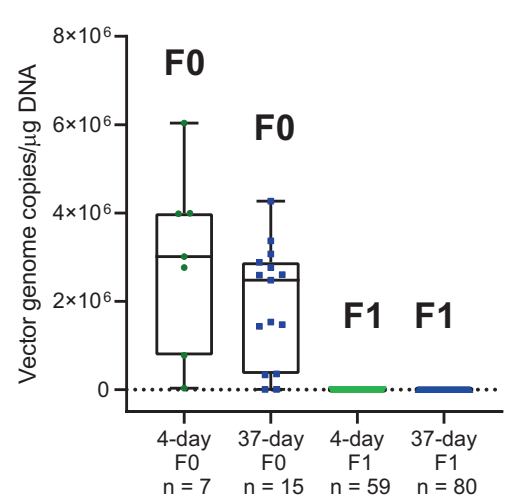

B)

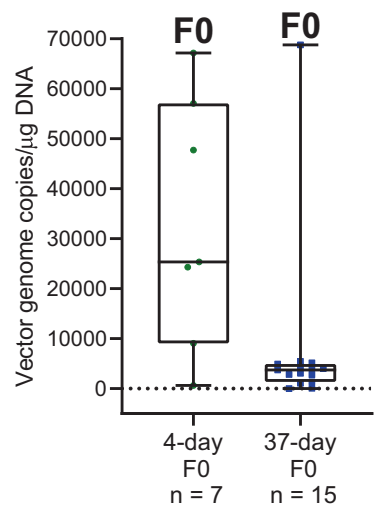

C)

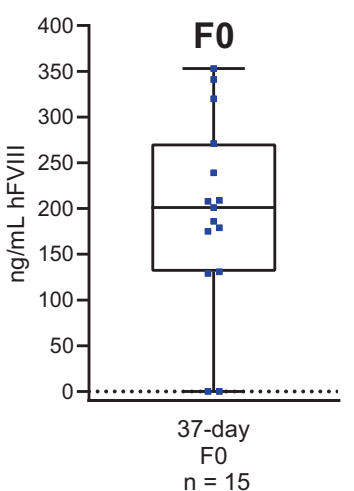

Fig. 2 Levels of vector DNA and transgene protein. For the 22 F0 males who received AAV5-hFVIII-SQ and sired offspring after mating at 4 or 37 days post-dose, vector genome copy number in individual tissue samples from (A) liver or (B) testes, and (C) hFVIII-SQ protein plasma levels. Data are shown for the 22 F0 males who received AAV5-hFVIII-SQ and sired offspring and their 139 F1 male and female pups. No vector genome DNA was detected in any F0 male who received a vehicle injection. F0 males mated at 4 days post-dose were not evaluated for $\mathrm{hFVIII}$ protein presence. For the hFVIII protein assay, the LLOQ was $2.35 \mathrm{ng} / \mathrm{mL}$; samples with protein levels below the LLOQ are shown as $0 \mathrm{ng} / \mathrm{mL}$. hFVIII human Factor VIII, LLOQ lower limit of quantitation.

and F1 pups necessary to assess the probability of germline transmission, assuming a certain level of risk. Based on the model, the number of mice required to be tested would increase as the study power increases or as the assumed probabilities of germline transmission decrease. After determining that no germline transmission had occurred experimentally, the formula used to calculate the study power was used to estimate the confidence level that the risk of germline transmission is lower than the assumptions made in the model, based on the actual number of F1 pups sired by each F0 male. Power and confidence calculations were performed in R v3.5.2 (R Foundation for Statistical Computing, Vienna, Austria).

\section{RESULTS}

\section{In vivo observations}

Except for one male mouse who received AAV5-hFVIII-SQ, all F0 male mice dosed with vehicle or AAV5-hFVIII-SQ survived until scheduled euthanasia and appeared normal throughout the study. There were no clinical observations, changes in body weight, or necropsy observations that could be attributed to AAV5-hFVIII-SQ. The death of 1 mouse was considered unrelated to AAV5-hFVIII-SQ administration or protein expression, because it occurred $2 \mathrm{~h}$ after dosing, and there were no post-mortem indications. Although the study was designed to assess the risk of germline transmission and not the impact of AAV5-hFVIII-SQ on fertility or other reproductive parameters, there were no apparent changes in fertility parameters such as the number of pups born per mating in males that received AAV5-hFVIII-SQ relative to mice that received vehicle. In addition, there was no effect of AAV5-hFVIII-SQ on maternal behaviors or litter observations, as well as no clinical findings, body weight changes, or necropsy observations in F1 offspring.

\section{AAV5-hFVIII-SQ transduction in F0 males}

hFVIII-SQ DNA was detected in the livers of all F0 males who received AAV5-hFVIII-SQ mated at 4 days $(n=16)$ or 37 days postdose $(n=34)$, consistent with successful gene transfer (Fig. 2A). In livers of these F0 males mated at 4 days, transgene DNA levels ranged from 14341 to 6036022 mean vector copies (vc)/ $\mu \mathrm{g}$ DNA tested, and in F0 males mated at 37 days, liver transgene DNA levels ranged from 1725 to 4267407 mean vc/ug DNA tested. Transgene DNA was also detected at lower levels in the testes of all FO males mated at 4 days (range, 138 to 84907 mean vc/ $\mu \mathrm{g}$

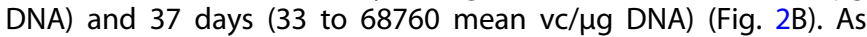
expected, no F0 males dosed with vehicle control were positive for hFVIII-SQ DNA in their livers or testes. The plasma of 28 of 33 evaluated F0 males mated at 37 days had detectable hFVIII-SQ protein, ranging from 64 to $387 \mathrm{ng} / \mathrm{mL}$ (Fig. 2C). None of the six evaluated vehicle-dosed F0 mice mated at 37 days post-dose had $\mathrm{hFVIII-SQ} \mathrm{protein} \mathrm{detected} \mathrm{in} \mathrm{plasma.} \mathrm{The} \mathrm{presence} \mathrm{of} \mathrm{hFVIII-SQ}$ DNA in liver and testes and the corresponding detection of hFVIIISQ protein in plasma further confirms that $\mathrm{F} 0$ males that received AAV5-hFVIII-SQ were successfully transduced and, therefore, had the theoretical potential for vertical transmission of AAV5-hFVIII$\mathrm{SQ}$ to the next generation. By experimental design, hFVIII-SQ protein in plasma was not measured in F0 males mated at the earlier timepoint, because very low or no transgene expression was expected, given that euthanasia occurred soon after AAV5hFVIII-SQ administration. However, FO males mated at 4 days demonstrated high levels of hFVIII-SQ DNA in their livers and relatively lower levels of hFVIII-SQ DNA in their testes.

\section{Germline transmission in $\mathbf{F 1}$ mice}

In total, 59 and $80 \mathrm{~F} 1$ male and female offspring from AAV5-hFVIIISQ-dosed F0 males mated at 4 and 37 days, respectively, and 26 and 51 F1 males and females sired by vehicle-dosed F0 males mated at 4 and 37 days, respectively, were assessed for the presence of transgene DNA in the liver. No F1 mice sired by F0 males dosed with vehicle were positive for transgene DNA. More importantly, no transgene DNA was detected in the livers of F1 offspring of F0 males dosed with $6 \times 10^{13} \mathrm{vg} / \mathrm{kg}$ AAV5-hFVIII-SQ (Fig. 2A).

Based on the 2-stage statistical model that took into account 22 F0 males that received AAV5-hFVIII-SQ and the 139 F1 pups these males sired, there is $99.2 \%$ confidence that the risk of germline transmission is $<5 \%$ (Table 1 ). A visual representation of possible confidence levels derived from the model, given various assumed values of $P_{1}$ and $P_{2}$, is presented in Fig. 3 .

\section{DISCUSSION}

In this study, sexually mature male B6.129S6-Rag2 ${ }^{\text {tm1Fwa }}$ N12 mice (F0) were dosed with $6 \times 10^{13} \mathrm{vg} / \mathrm{kg}$ AAV5-hFVIII-SQ and subsequently bred with naïve females. Germline transmission potential was evaluated at two different mating time points following AAV5-hFVIII-SQ administration. Mating pairs were set up 4 days after dosing, when transgene DNA concentration was estimated to be highest in semen based on AAV5-hFVIII-SQ clinical data [6], and at 37 days after dosing, when the spermatogenesis cycle was expected to be complete in mice [19-21]. Delayed mating at 37 days after AAV5-hFVIII-SQ administration could potentially 
Table 1. Study confidence that $\geq 1 \mathrm{hFVIII-SQ} \mathrm{germline} \mathrm{transmission}$ event would have been detected given assumed probabilities for the risk of germline transmission.

\begin{tabular}{|llll|}
$\begin{array}{l}\text { Overall probability of } \\
\text { germline transmission }(\boldsymbol{P})\end{array}$ & $\boldsymbol{P}_{\mathbf{1}}$ & $\boldsymbol{P}_{\mathbf{2}}$ & $\begin{array}{l}\text { Confidence/ } \\
\text { power }\end{array}$ \\
\hline 0.050 & 0.316 & 0.158 & 0.992 \\
\hline 0.040 & 0.283 & 0.141 & 0.982 \\
\hline 0.030 & 0.245 & 0.122 & 0.954 \\
\hline 0.020 & 0.200 & 0.100 & 0.884 \\
\hline 0.015 & 0.173 & 0.087 & 0.810 \\
\hline
\end{tabular}

$P=P_{1} * P_{2}$, where $P_{1}$ is the assumed probability an F0 male acquires and transmits transgene DNA to an F1 offspring, and $P_{2}$ is the assumed probability an F1 offspring inherits and retains the transgene DNA. Confidence values were calculated using Eq. 1 as stated in the Methods section and were based on the number of mice born to each of the 22 F0 males that received AAV5-hFVIII.

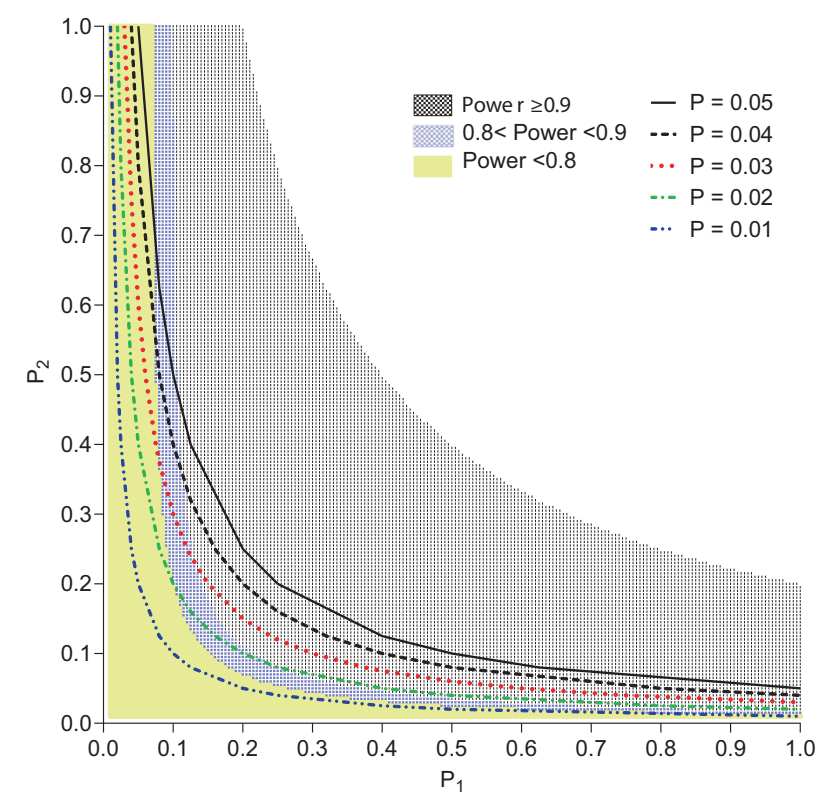

Fig. 3 Contour plot showing the relationship between study confidence, $\boldsymbol{P}_{1}$, and $\boldsymbol{P}_{\mathbf{2}}$ resulting from the 2 -stage statistical model. Results were generated with Eq. 1. $P_{1}$ is the probability an F0 male acquires and transmits transgene DNA to an F1 offspring. $P_{2}$ is the probability an $\mathrm{F} 1$ offspring inherits and retains the transgene DNA. $P=P_{1} * P_{2}$ is the overall probability of a germline transmission; lines represent combinations of $P_{1} * P_{2}$ that would result in $P$, probability of germline transmission, between 0.01 and 0.05 . The colored regions represent the combinations of $P_{1}$ and $P_{2}$, covering various ranges of study confidence, using the $22 \mathrm{FO}$ males who received AAV5-hFVIII-SQ and their combined 139 F1 offspring.

enable the transduction of early-stage spermatogonia that would then mature into sperm ready for fertilization at the time of mating. These two timepoints were chosen as they were estimated to have the highest potential for germline transmission. While transduction and genomic integration of transgene DNA could in theory occur at any stage of spermatogenesis, exhaustively testing every stage or through several spermatogenesis cycles is not feasible. While transgene DNA was detected in the testes of these F0 males, no instances of germline transmission were observed, as no transgene DNA was detected in any of the 139 pups (F1) they sired.

Our results are consistent with previous in vitro and in vivo studies that showed that germline transmission is unlikely following AAV-mediated gene transfer. For instance, exposing mouse sperm to high concentrations of AAV2 vectors did not result in germline transmission when followed by in vitro fertilization [23]. Previous in vivo approaches to assess the risk of germline transmission in rats, mice, or rabbits included the delivery of AAV vectors systemically or directly into the gonads, followed by an assessment of gonadal tissue or gametes for the presence of transgene DNA [8, 10, 12, 16, 23]. However, studies examining gametes are typically only feasible with a relatively small number of animals, and visualization of transgene DNA using DNA-hybridization techniques can only be performed in a fraction of the total gamete population, particularly when assessing the male reproductive tract. In other animal studies, AAV vectors were administered systemically to males, which were then mated with naïve females, and the resulting offspring of such pairings were then evaluated for the presence of transgene DNA $[11,24,25]$. Unlike the current study, most of these studies were performed without power calculations or other statistical considerations to provide a confidence level to determine the probability of germline transmission.

To incorporate statistical considerations into the experimental design and data interpretation, we developed a novel 2-stage statistical model that assumed two distinct events needed to occur for successful germline transmission: (1) FO males that received AAV5-hFVIII-SQ acquired transgene DNA and transmitted it to the F1 generation, and (2) F1 generation mice inherited and retained the transgene DNA. This statistical model was initially used to perform a power analysis calculation to identify the minimal number of F0 and F1 mice necessary to detect at least one successful germline transmission event, based on hypothetical probabilities assigned to the two transmission steps defined above. Importantly, the minimal number of F0 progenitors utilized, as determined by the model, ensured that the contribution of each F0 male to the F1 generation was appropriately calculated and avoided underestimating germline transmission risk by using too few males. Once the experiments were completed, the data were analyzed by the model to establish a confidence level supported by the actual results. Given that no AAV5-hFVIII-SQ DNA was detected in F1 offspring, the model supports a 99.2\% confidence that the risk of germline transmission of AAV5-hFVIII-SQ is below $5 \%$. This novel method provides a level of statistical confidence in our results that has previously been lacking from studies of germline transmission, as an infinite number of mice would be required to prove that germline transmission does not occur following AAV5-hFVIII-SQ therapy, or any other gene therapy.

The low potential for germline transmission observed in this study was expected, given the engineered design of AAV vectors, including their inability to replicate [4]. Genome integration is likely to be a required step for successful AAV-mediated germline transmission to occur. Relatively low levels of genome integration cannot be ruled out, as shown in a number of published reports; [26-31] however, given the largely episomal and nonreplicating nature of transduced AAV vector DNA [32-41], even a rare event of episomal germline transmission would be highly unlikely to result in multigenerational, stable transgene inheritance. Overall, our results show that germline transmission of AAV5-hFVIII-SQ is highly unlikely.

\section{DATA AVAILABILITY}

Materials and protocols will be distributed to qualified scientific researchers for noncommercial, academic purposes. The AAV5-hFVIII-SQ vector and the AAV5-hFVIII-SQ vector sequence are part of an ongoing development program, and they will not be shared.

\section{REFERENCES}

1. Iorio A, Stonebraker JS, Chambost H, Makris M, Coffin D, Herr C, et al. Establishing the prevalence and prevalence at birth of hemophilia in males: A meta-analytic approach using national registries. Ann Intern Med. 2019;171:540-6. 
2. Mazepa MA, Monahan PE, Baker JR, Riske BK, Soucie JM, Network USHTC. Men with severe hemophilia in the United States: birth cohort analysis of a large national database. Blood. 2016;127:3073-81.

3. Srivastava A, Santagostino E, Dougall A, Kitchen S, Sutherland M, Pipe SW, et al. WFH guidelines for the management of hemophilia, 3rd edition. Haemophilia. 2020;26:1-158.

4. Bunting S, Zhang L, Xie L, Bullens S, Mahimkar R, Fong S, et al. Gene therapy with BMN 270 results in therapeutic levels of FVIII in mice and primates and normalization of bleeding in hemophilic mice. Mol Ther. 2018;26:496-509.

5. Pasi KJ, Laffan M, Rangarajan S, Robinson TM, Mitchell N, Lester W, et al. Persistence of haemostatic response following gene therapy with valoctocogene roxaparvovec in severe haemophilia A. Haemophilia. 2021;27:947-56.

6. Rangarajan S, Walsh L, Lester W, Perry D, Madan B, Laffan M, et al. AAV5-Factor VIII gene transfer in severe hemophilia A. N Engl J Med. 2017;377:2519-30.

7. Pasi KJ, Rangarajan S, Mitchell N, Lester W, Symington E, Madan B, et al. Multiyear follow-up of AAV5-hFVIII-SQ gene therapy for hemophilia A. N Engl J Med. 2020;382:29-40.

8. Han S, Park S-J, Yoo G, Kim J-Y, Lee S, Hwang J, et al. Biodistribution and shedding studies of adeno-associated virus 5 in C57BL/ 6 mice by quantitative PCR. Mol Ther. 2018;26:190.

9. Rajasekaran S, Thatte J, Periasamy J, Javali A, Jayaram M, Sen D, et al. Infectivity of adeno-associated virus serotypes in mouse testis. BMC Biotechnol. 2018;18:70.

10. Ferla R, Marteau J-B, Pouillot S, Kozarsky K, Brown J, Galimberti S, et al. GLPcompliant non-clinical safety and biodistribution of a recombinant AAV2/8 vector administered intravenously for treatment of mucopolysaccharidosis type VI. Mol Ther. 2016:24:S185.

11. Ferla R, Alliegro M, Marteau JB, Dell'Anno M, Nusco E, Pouillot $S$, et al. Nonclinical safety and efficacy of an AAV2/8 vector administered intravenously for treatment of mucopolysaccharidosis type VI. Mol Ther Methods Clin Dev. 2017;6:143-58.

12. Favaro $P$, Finn JD, Siner Jl, Wright JF, High KA, Arruda VR. Safety of liver gene transfer following peripheral intravascular delivery of adeno-associated virus (AAV) -5 and AAV- 6 in a large animal model. Hum Gene Ther. 2011;22:843-52.

13. Ware T, Murrey $\mathrm{D}, \mathrm{McCarty} \mathrm{D}, \mathrm{Fu} \mathrm{H}$. Normalized survival and permanent restoration of NAGLU activity in the CNS, PNS and somatic tissues in MPS IIIB mice after a single intravenous rAAV9-hNAGLU gene delivery. Mol Ther. 2012;20: S13.

14. Mattar CN, Nathwani A, Waddington S, Dighe N, Kaeppel C, Nowrouzi A, et al. Outcomes of AAV8 and AAV5-mediated fetal gene transfer at $0.9 \mathrm{~g}$ in non-human primates. Mol Ther. 2011;19:S18

15. Schuettrumpf J, Liu JH, Couto LB, Addya K, Leonard DG, Zhen Z, et al. Inadvertent germline transmission of AAV2 vector: findings in a rabbit model correlate with those in a human clinical trial. Mol Ther. 2006;13:1064-73.

16. Pachori AS, Melo LG, Zhang L, Loda M, Pratt RE, Dzau VJ. Potential for germ line transmission after intramyocardial gene delivery by adeno-associated virus. Biochem Biophys Res Commun. 2004;313:528-33.

17. Arruda VR, Fields PA, Milner R, Wainwright L, De Miguel MP, Donovan PJ, et al. Lack of germline transmission of vector sequences following systemic administration of recombinant AAV-2 vector in males. Mol Ther. 2001;4:586-92.

18. Shinkai Y, Rathbun G, Lam KP, Oltz EM, Stewart V, Mendelsohn M, et al. RAG-2deficient mice lack mature lymphocytes owing to inability to initiate $V(D) J$ rearrangement. Cell. 1992;68:855-67.

19. Oakberg EF. Duration of spermatogenesis in the mouse and timing of stages of the cycle of the seminiferous epithelium. Am J Anat. 1956;99:507-16.

20. Dadoune JP, Alfonsi MF. Autoradiographic investigation of sperm transit through the male mouse genital tract after tritiated thymidine incorporation. Reprod Nutr Dev. 1984;24:927-35.

21. Gervasi MG, Visconti PE. Molecular changes and signaling events occurring in spermatozoa during epididymal maturation. Andrology. 2017;5:204-18.

22. National Research Council (US). Committee for the update of the guide for the care and use of laboratory animals. guide for the care and use of laboratory animals. 8th ed. National Academies Press (US): Washington (DC); 2011.

23. Couto L, Parker A, Gordon JW. Direct exposure of mouse spermatozoa to very high concentrations of a serotype-2 adeno-associated virus gene therapy vector fails to lead to germ cell transduction. Hum Gene Ther. 2004;15:287-91.

24. Royo A, González-Aseguinolaza G, Aizpun I, Rodríguez A, Cornet M, del Mar Municio $M$ et al. No longitudinal transmission of AAV5-PBGD vector DNA in mice. Toxicol Lett. 2013;221:S213-14.

25. Jakob M, Muhle C, Park J, Weiss S, Waddington S, Schneider H. No evidence for germ-line transmission following prenatal and early postnatal AAV-mediated gene delivery. J Gene Med. 2005;7:630-7.
26. Niemeyer GP, Herzog RW, Mount J, Arruda VR, Tillson DM, Hathcock J, et al. Long-term correction of inhibitor-prone hemophilia $B$ dogs treated with liver-directed AAV2-mediated factor IX gene therapy. Blood 2009;113:797-806.

27. Chandler RJ, Sands MS, Venditti CP. Recombinant adeno-associated viral integration and genotoxicity: insights from animal models. Hum Gene Ther 2017;28:314-22.

28. Nakai $H$, Montini E, Fuess $S$, Storm TA, Grompe M, Kay MA. AAV serotype 2 vectors preferentially integrate into active genes in mice. Nat Genet. 2003;34:297-302.

29. Nakai H, Wu X, Fuess S, Storm TA, Munroe D, Montini E, et al. Large-scale molecular characterization of adeno-associated virus vector integration in mouse liver. J Virol. 2005;79:3606-14.

30. Nguyen GN, Everett JK, Kafle S, Roche AM, Raymond HE, Leiby J, et al. A long-term study of AAV gene therapy in dogs with hemophilia A identifies clonal expansions of transduced liver cells. Nat Biotechnol. 2021;39:47-55.

31. Kazazian HH Jr. An estimated frequency of endogenous insertional mutations in humans. Nat Genet. 1999;22:130.

32. Afione SA, Conrad CK, Kearns WG, Chunduru S, Adams R, Reynolds TC, et al. In vivo model of adeno-associated virus vector persistence and rescue. J Virol. 1996;70:3235-41.

33. Duan D, Sharma P, Yang J, Yue Y, Dudus L, Zhang Y, et al. Circular intermediates of recombinant adeno-associated virus have defined structural characteristics responsible for long-term episomal persistence in muscle tissue. J Virol. 1998;72:8568-77.

34. Vincent-Lacaze N, Snyder RO, Gluzman R, Bohl D, Lagarde C, Danos O. Structure of adeno-associated virus vector DNA following transduction of the skeletal muscle. J Virol. 1999;73:1949-55.

35. Nakai H, Storm TA, Kay MA. Recruitment of single-stranded recombinant adenoassociated virus vector genomes and intermolecular recombination are responsible for stable transduction of liver in vivo. J Virol. 2000;74:9451-63.

36. Nakai H, Yant SR, Storm TA, Fuess S, Meuse L, Kay MA. Extrachromosomal recombinant adeno-associated virus vector genomes are primarily responsible for stable liver transduction in vivo. J Virol. 2001;75:6969-76.

37. Song S, Laipis PJ, Berns KI, Flotte TR. Effect of DNA-dependent protein kinase on the molecular fate of the rAAV2 genome in skeletal muscle. Proc Natl Acad Sci U S A. 2001;98:4084-8.

38. Nakai $H$, Thomas $C E$, Storm TA, Fuess $S$, Powell $S$, Wright JF, et al. A limited number of transducible hepatocytes restricts a wide-range linear vector dose response in recombinant adeno-associated virus-mediated liver transduction. J Virol. 2002;76:11343-9.

39. Song S, Lu Y, Choi YK, Han Y, Tang Q, Zhao G, et al. DNA-dependent PK inhibits adeno-associated virus DNA integration. Proc Natl Acad Sci U S A 2004;101:2112-6.

40. Penaud-Budloo M, Le Guiner C, Nowrouzi A, Toromanoff A, Cherel Y, Chenuaud P, et al. Adeno-associated virus vector genomes persist as episomal chromatin in primate muscle. J Virol. 2008;82:7875-85.

41. Mclntosh J, Lenting PJ, Rosales C, Lee D, Rabbanian S, Raj D, et al. Therapeutic levels of FVIII following a single peripheral vein administration of rAAV vector encoding a novel human factor VIII variant. Blood. 2013;121:3335-44.

\section{ACKNOWLEDGEMENTS}

Medical writing support was provided by Kathleen Pieper, PhD, of AlphaBioCom, LLC, and funded by BioMarin Pharmaceutical Inc. Funding for this study was provided by BioMarin Pharmaceutical Inc.

\section{AUTHOR CONTRIBUTIONS}

CF, CAON, and CS contributed to study design. JA oversaw conduct of the study. CS developed the statistical model and performed the power analyses. EK performed the molecular analyses. JS and JH provided pharmacodynamic assessments. AVT and CV oversaw the molecular analyses. SC performed histopathology review. All authors contributed to interpretation of the results, critically reviewed the manuscript during drafting, and provided approval before submission.

\section{COMPETING INTERESTS}

CF, JS, and SC are former employees of BioMarin Pharmaceutical Inc. and may own stock. CS, JA, EK, JH, AVT, CV, and CAON are employees and shareholders of BioMarin Pharmaceutical Inc. 


\section{ADDITIONAL INFORMATION}

Supplementary information The online version contains supplementary material available at https://doi.org/10.1038/s41434-022-00318-5.

Correspondence and requests for materials should be addressed to Charles A. O’Neill.

Reprints and permission information is available at http://www.nature.com/ reprints

Publisher's note Springer Nature remains neutral with regard to jurisdictional claims in published maps and institutional affiliations.
Open Access This article is licensed under a Creative Commons Attribution 4.0 International License, which permits use, sharing, adaptation, distribution and reproduction in any medium or format, as long as you give appropriate credit to the original author(s) and the source, provide a link to the Creative Commons license, and indicate if changes were made. The images or other third party material in this article are included in the article's Creative Commons license, unless indicated otherwise in a credit line to the material. If material is not included in the article's Creative Commons license and your intended use is not permitted by statutory regulation or exceeds the permitted use, you will need to obtain permission directly from the copyright holder. To view a copy of this license, visit http://creativecommons. org/licenses/by/4.0/.

(c) The Author(s) 2022 